\title{
Taylor Spatial Frame in Treatment of Equinus Deformity
}

\author{
Sherif Dabash ${ }^{1}$, Eric Potter ${ }^{2}$, Gregory Catlett ${ }^{3}$, William McGarvey ${ }^{4}$
}

\begin{abstract}
Background: An equinus deformity interferes with activities of daily living. Correction of the deformity ranges from conservative (heel cord stretching, orthotics) to surgical treatment (Baumann, Strayer, Achilles lengthening, soft tissue releases). Severe contractures increase surgical intervention with extensive dissections to release soft tissues. This study investigated the clinical outcomes of gradual overcorrection using a Taylor spatial frame (TSF) with tendo-Achilles lengthening (TAL) added as necessary.

Materials and methods: This retrospective chart review evaluated patients with significant equinus treated with a TSF at a single large tertiary referral centre. Data collected included: diagnosis; patient demographics; laterality; time in frame; additional procedures; complications; degree of equinus deformity preoperatively and at every follow-up visit. Patients were followed at 1 week, 3 weeks, 6 weeks, 3 months, and 6 months intervals, and yearly thereafter.

Results: Twenty-four patients (26 procedures) were treated with a TSF for equinus and had complete preoperative and follow-up measurements over 2 years. The angle of deformity increased from a preoperative -21.5 (range, -69.0 to -1.0 ) degrees to a postoperative 4.9 (range, -17.0 to 17.0 ) degrees $(z=-4.4573, p=0.0001, N=26$, Wilcoxon signed-rank test). A secondary outcome was a weak association (not statistically significant) between time in the TSF and the postoperative deformity angle. Four complications occurred during the follow-up (two pin site infections, one broken pin, and one plantar abscess). Three patients had recurrence of equinus deformity at time of last follow-up.

Conclusion: Using a TSF for correcting severe, fixed equinus contractures of the ankle joint is successful with minimal soft tissue-related complications. Overcorrection should be achieved in order to compensate for the loss of some dorsiflexion after frame removal. No added benefit was observed from having the frame on for a long time after correcting the deformity. Adding TAL is not necessary in all cases and required only in severe deformities of more than $25^{\circ}$.

Keywords: Baumann, Equinus, Foot and ankle deformities, Soft tissue contractures, Strayer, Taylor spatial frame, Tendo-Achilles lengthening. Strategies in Trauma and Limb Reconstruction (2020): 10.5005/jp-journals-10080-1452
\end{abstract}

\section{INTRODUCTION}

An equinus contracture (EC) of the ankle debilitates and interferes with activity and quality of life. The deformity is associated with post-traumatic neuromuscular injury, wound or burn scar contracture, cerebral palsy, Achilles tendon rigidity, spasticity of the gastrocnemius or soleus, prolonged immobilisation in plantarflexion, diabetic neuropathy, and idiopathic neuropathy. ${ }^{1-7}$ The EC contributes to the alteration of normal gait pattern, reduction of stride length, reduction of gait velocity, alteration of the biomechanics of adjacent and distal joints, chronic pain, and has been associated with increased plantar pressure and ulceration. ${ }^{5,6,8,9}$

Many treatment options exist to address ECs. Non-operative methods include heel cord stretching and the use of orthotics (e.g., heel lift inserts). For more severe EC requiring operative intervention, options include releasing the gastrocnemius with the Strayer procedure; Achilles lengthening; posterior capsular release; multiapproach soft tissue releases; and distraction osteogenesis using the llizarov technique. ${ }^{1,10-15}$ Large contractures may require extensile incisions with broad dissections and aggressive release of soft tissues. While current operative approaches can be effective at treating the original deformity, there is a high risk of EC recurrence. $3,7,16,17$

Several studies advocate utilising external fixation for placing the foot in a zero-degree plantigrade position after correction in a frame. ${ }^{13,18}$ We postulate that correction of the equinus deformity with the frame only without major soft tissue releases is sufficient for correction, and that overcorrection prevents the risk of contracture recurrence and regression to equinus deformity.

\begin{abstract}
1Department of Orthopedic Surgery, University of Louisville, Kentucky, USA; Department of Orthopedic Surgery, Ain Shams University, Cairo, Egypt

${ }^{2}$ Orthopedic Department, Baylor Scott and White Research Institute, Dallas, Texas, USA

${ }^{3,4}$ Department of Orthopedic Surgery, The University of Texas Health Science Center at Houston, Texas, USA

Corresponding Author: Sherif Dabash, Department of Orthopedic Surgery, University of Louisville, Kentucky, USA, e-mail: sdabash@ gmail.com

How to cite this article: Dabash S, Potter E, Catlett G, et al. Taylor Spatial Frame in Treatment of Equinus Deformity. Strategies Trauma Limb Reconstr 2020;15(1):28-33.
\end{abstract}

Source of support: Nil

Conflict of interest: None

This study investigates the clinical outcomes of gradual EC overcorrection using TSF with tendo-Achilles lengthening (TAL) added as necessary.

\section{Materials and Methods}

An internal review board approved a retrospective chart review on a consecutive series of patients with significant ECs of the ankle who underwent correction with external fixation with a Taylor spatial frame (TSF, Smith \& Nephew, Memphis, Tennessee, USA) by the senior author between January 2009 and December 2014. The equinus deformity was diagnosed by clinical exam

() The Author(s). 2020 Open Access This article is distributed under the terms of the Creative Commons Attribution 4.0 International License (https://creativecommons. org/licenses/by-nc/4.0/), which permits unrestricted use, distribution, and non-commercial reproduction in any medium, provided you give appropriate credit to the original author(s) and the source, provide a link to the Creative Commons license, and indicate if changes were made. The Creative Commons Public Domain Dedication waiver (http://creativecommons.org/publicdomain/zero/1.0/) applies to the data made available in this article, unless otherwise stated. 
and X-rays. The angle of deformity was assessed preoperatively and postoperatively at 1 week, 3 weeks, 6 weeks, 3 months, and 6 months intervals, and yearly thereafter. Patients were followed for 2 years postoperatively. The TSF was removed when the expected correction was achieved with the TSF software and patients spent a brief period of immobilisation in a short leg walking cast.

Inclusion criteria were all patients who presented with a fixed EC of ankle with a minimum 4-month clinical follow-up and at least 3 postop foot and ankle radiographs. There were no exclusion criteria. Patient data were collected retrospectively. The variables recorded were diagnosis, age, gender, laterality, date of frame application, date of frame removal, time in frame, additional procedures performed at the time of frame application, documented complications, preoperative and postoperative serial radiographic and clinical measurement of ankle equinus.

All angles recorded were based on the anatomical neutral position of the foot at $90^{\circ}$ from the tibia. This neutral position was converted to zero degrees, so that all negative angle measurements indicated plantar flexion for the foot (equinus deformity), and all positive angle measurements indicated dorsiflexion.

Calculations and plots of the median change-over-time ankle flexion measurements were performed in Excel (Microsoft). The Wilcoxon signed-rank test was used to compare differences between the median preoperative and 6-month follow-up measurements. The Pearson correlation was used to examine the mean postoperative measurement as a function of time in the TSF.

\section{Surgical Technique}

No tourniquet is used in the procedure. A TAL is performed on most patients through a percutaneous Z-type incision to give some degree of correction and to decrease stresses on the Achilles tendon during the gradual correction. Patients with less severe rigid deformities (more than $20^{\circ}$ arc of dorsiflexion from maximum and resisted plantar flexion) do not undergo this step and proceed directly to external fixator application.

The external fixator construct consists of one ring applied orthogonal to the distal third of the tibial shaft, usually a $155 \mathrm{~mm}$ diameter ring, which is stabilised with a tensioned $1.8 \mathrm{~mm}$ wire and one to three anteromedial half-pins to provide a stable construct against rotation and angular flexion. If needed, an extra ring is applied proximally and connected to the distal ring. The half-pins are $6.0 \mathrm{~mm}$ hydroxyapatite-coated pins and are placed after drilling with a $4.8 \mathrm{~mm}$ drill. The foot ring fixator consists of transverse and oblique tension wires through the forefoot and the calcaneus. A single axial half-pin is used posteriorly in the calcaneus for extra fixation. All wires are appropriately tensioned until stable fixation is achieved.

Six struts are connected from the proximal tibial construct to the foot ring. The TSF program utilises the ankle selection to provide proper metrics for deformity correction (Figs 1 and 2). The virtual hinge is modified to utilise the talar dome as the fulcrum, and the arc of motion with the plafond as reference after distraction. Five-millimeter distraction of the ankle joint is usually applied to facilitate the correction process, while $7 \mathrm{~mm}$ distraction is used if joint arthritis is notable.

\section{Postoperative Period}

On postoperative day 3 , the patient starts adjusting the frame according to the schedule of correction provided (Fig. 3). The rate

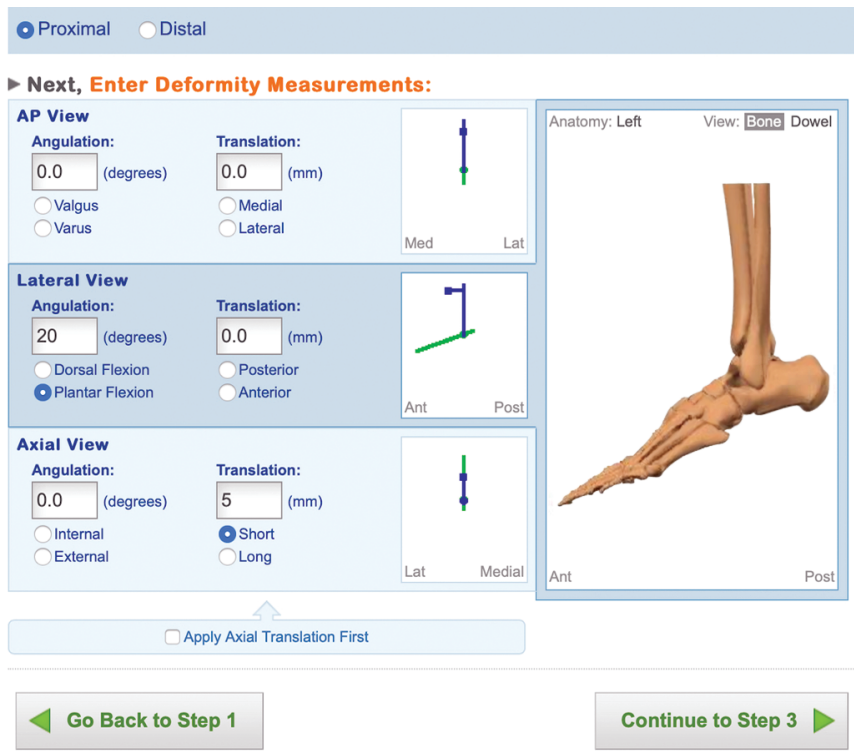

Fig. 1: Equinus deformity

of correction is $2 \mathrm{~mm} /$ day. The rate of correction and adjustments are titrated based on the patient's tolerance to pain or if numbness occurs due to nerve stretching. Patients do not bear weight during the correction period because of the equinus position. Once the target correction (overcorrection between $15^{\circ}$ and $20^{\circ}$ dorsiflexion) is achieved, the frame is kept in place for an extra 2 weeks allowing for soft tissue adaptation. The frame is then removed in the operating room and a cast applied at maximum dorsiflexion. Patients are allowed to bear weight in the cast for 6 weeks.

\section{Results}

Twenty-four patients underwent 26 procedures for ankle equinus deformity. There were 19 male patients (73.1\%) and 7 female patients (26.9\%) with a median age of 33.9 (range, 15.1-73.3) years at the time of surgery and fixation with the TSF.

The aetiology for equinus in the 26 cases were 11 post-traumatic (42.3\%); 6 traumatic brain injury (TBI) (19.2\%); 2 status postsurgical (7.7\%); 1 Charcot-Marie-Tooth (3.8\%); 1 prolonged bed rest/ intensive care unit (ICU) stay (3.8\%); 1 spinal cord pathology (3.8\%); 1 stroke (3.8\%); 1 lower extremity burn (3.8\%); 1 Parkinson's (3.8\%); 1 idiopathic cause (3.8\%).

Two patients accounted for four procedures in our study sample. One patient had suffered a TBI and was treated for both ankles at the same time. The other patient also sustained a TBI and presented with equinus of the right ankle but was treated subsequently for equinus in his left ankle 482 days later. Seven of 26 ankles required additional operative interventions at the time of equinus repair in the form of TAL (Table 1).

Preoperative and postoperative deformity angles were compared using the data from patients who had complete preoperative and 2 years' follow-up measurements. The angle increased from a preoperative of -20.0 (95\% Cl: -25.13 to -15.64$)$ degrees to a 6 month postoperative 7.5 (95\% Cl: 6.98-12.63) degrees ( $p=0.001)$ (Fig. 4 and Table 2). The median time in frame was 50 (95\% Cl: 41.09-58.91) days. Ankle flexion angle at the time of TSF removal was considered as a function of time in the TSF in 26 patients who had complete 6 month follow-up measurements. A Pearson correlation scatterplot demonstrated a weakly positive 

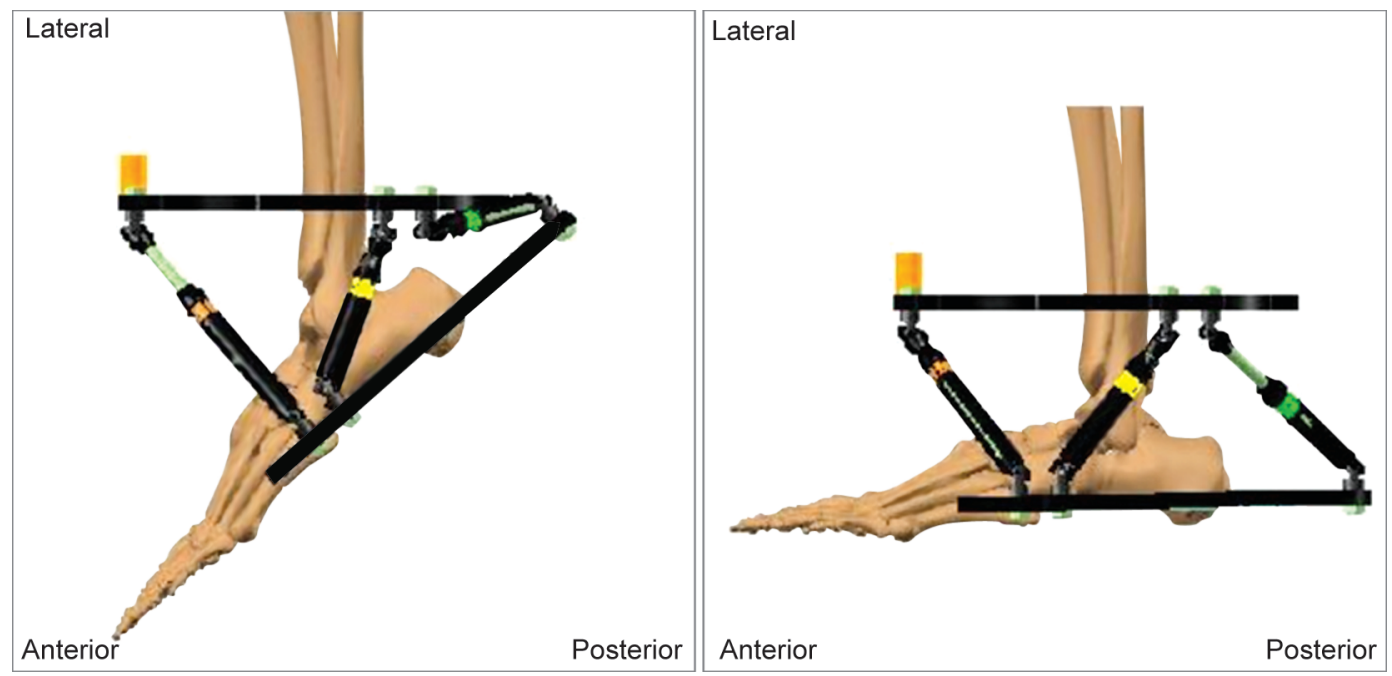

Fig. 2: Frame mount before and after correction of the deformity

\begin{tabular}{|c|c|c|c|c|c|c|c|}
\hline WkDay & Day & Strut 1 [ & Strut 2 & Strut 3 & Strut 4 & Strut 5 & Strut 6 \\
\hline Fri & 0 & $140^{a}$ & $130^{c}$ & $70^{d}$ & $70^{f}$ & $130^{h}$ & 140 \\
\hline Sat & 1 & 138 & 129 & 71 & 71 & 131 & 141 \\
\hline Sun & 2 & 136 & 128 & 72 & 72 & 131 & 142 \\
\hline Mon & 3 & 134 & 128 & 72 & 73 & 132 & 144 \\
\hline Tue & 4 & 132 & 127 & 73 & 73 & 133 & 145 \\
\hline Wed & 5 & 130 & 126 & 74 & 74 & 133 & 146 \\
\hline Thu & 6 & 128 & 125 & $75^{e}$ & $75^{g}$ & 134 & 147 \\
\hline Fri & 7 & $125^{b}$ & 124 & $76^{e}$ & $76^{\mathrm{g}}$ & 134 & 149 \\
\hline Sat & 8 & $123^{b}$ & 124 & $76^{e}$ & 77 & 135 & 150 \\
\hline Sun & 9 & $121^{b}$ & 123 & 77 & 78 & 136 & 151 \\
\hline Mon & 10 & $119^{b}$ & 122 & 78 & 79 & 136 & 152 \\
\hline Tue & 11 & $117^{b}$ & 121 & 79 & 79 & 137 & 153 \\
\hline Wed & 12 & 115 & 121 & 79 & 80 & 138 & 155 \\
\hline Thu & 13 & 113 & 120 & 80 & 81 & 138 & 156 \\
\hline Fri & 14 & 111 & 119 & 81 & 82 & 139 & 157 \\
\hline
\end{tabular}

Fig. 3: Deformity correction schedule

correlation that was not statistically significant between time in the TSF frame and postoperative deformity angle ( $r=0.1391$ ) (Fig. 5).

There were four complications (15.4\%). There were two pin site infections and one small plantar abscess that were debrided at the time of frame removal and treated with oral antibiotics. There were no long-term sequelae as a result of these infections. There was one broken fixator half-pin which required revision.

Three (11.5\%) patients had a recurrence of equinus deformity at last follow-up. The average deformity angle was -8.33 (range, -2.0 to -17.0$)$ degrees.

\section{Discussion}

Several treatment options are available for ECs depending on the severity of the deformity. ${ }^{19-21}$ Contemporary methods which focus

on extensive surgical release and dissection of the soft tissues have proven to be effective, albeit with a high risk of recurrence. ${ }^{3,7,16,17}$ It is possible that these methods are creating an iatrogenic injury with an increased risk for greater scar formation and wound contracture. The TSF offers an effective alternative for correcting the deformity without extensive release of the soft tissues. ${ }^{19,22,23}$ Our findings support our theory that overcorrection is the key to achieve a desired maximum dorsiflexion that prevents the recurrence of the deformity and allows for normal gait and stance later on (Fig. 6).

A recent study by Ferreira et al. on the treatment of equinocavus deformity using the multiplanar external fixator TSF reported findings agreeing with ours. ${ }^{24}$ Fadel et al. published in 2005 using the TSF for equinus deformity in two patients with one posttraumatic equinus and the second patient was a result of burn. They achieved full correction and rated their results as good. ${ }^{25}$

This unit manages EC using a TSF with overcorrection and additional procedures (TAL) added as necessary. The application of a multiplanar external fixator allows for gradual correction of severe, fixed ECs without traumatising the soft tissue envelope. The centre of rotation during software programming should be lateral with lateral frame offset centred at the lateral process of the talus, and the axial frame offset is posterior to prevent dislocation of the ankle joint during the correction.

This method of treating EC may be needed for patients at risk of poor wound healing or who would not tolerate an extensive open procedure. The advantages of the TSF over the llizarov external fixator is the ability to correct complicated deformities predictably and precisely. Using a virtual hinge with the TSF instead of the multiple hinges with the external fixator makes the correction of multiplanar deformity easier and with shorter learning curve for the surgeon.

This study demonstrated significantly improved dorsiflexion after overcorrection with a TSF from a mean preoperative deformity of $-21.5^{\circ}$ to a mean postoperative measure of $+4.9^{\circ}(p=0.0001)$. With this improvement, patients are capable of more natural mechanics of ambulation. This study did not find a significant correlation between maximum dorsiflexion and time the limb was held in a TSF $(R=0.1816, p=0.3746)$, which suggests that there may be no added benefit from having the frame for a long time after correction of the deformity. 
Table 1: Patient demographics, procedures, and complications

\begin{tabular}{|c|c|c|c|c|c|}
\hline Aetiology & Additional procedures & Complications & Age at TOS & Gender & Laterality \\
\hline 1. Post-traumatic & None & - & 23 & $M$ & $L$ \\
\hline 2. Post-traumatic & TAL & - & 24 & $\mathrm{~F}$ & L \\
\hline 3. Post-traumatic & TAL & - & 25 & $M$ & $\mathrm{R}$ \\
\hline 4. Post-traumatic & None & - & 34 & $M$ & $\mathrm{R}$ \\
\hline 5. Post-traumatic & TAL & - & 38 & $M$ & $\mathrm{R}$ \\
\hline 6. Post-traumatic & None & - & 48 & M & $\mathrm{R}$ \\
\hline 7. Post-traumatic & None & - & 50 & $M$ & $\mathrm{R}$ \\
\hline 8. Post-traumatic & None & - & 53 & $\mathrm{~F}$ & L \\
\hline 9. Post-traumatic & None & - & 53 & $M$ & $\mathrm{R}$ \\
\hline 10. Post-traumatic & None & Plantar abscess & 56 & $\mathrm{~F}$ & L \\
\hline 11. Post-traumatic & None & - & 57.5 & $M$ & L \\
\hline 12. TBI & TAL & - & 19 & $M$ & L \\
\hline 13. TBI & TAL & - & 31 & $M$ & $\mathrm{R}$ \\
\hline 14. TBI & None & Pin site infection & 33 & $M$ & L \\
\hline 15. TBI & None & - & 31.5 & $M$ & L \\
\hline 16. TBI & None & - & 31.5 & M & $\mathrm{R}$ \\
\hline 17. TBI & None & - & 26 & M & L \\
\hline 18. Surgical complication & None & - & 31 & $\mathrm{~F}$ & $\mathrm{R}$ \\
\hline 19. Surgical complication & None & - & 53 & $\mathrm{~F}$ & L \\
\hline 20. Charcot-Marie-Tooth & None & - & 15 & M & L \\
\hline 21. Prolonged bed rest/ICU stay & TAL & $\begin{array}{l}\text { Exfix pin breakage, requiring } \\
\text { frame revision }\end{array}$ & 50 & M & $\mathrm{R}$ \\
\hline 22. Spinal cord pathology & None & - & 25.5 & M & $\mathrm{R}$ \\
\hline 23. Stroke & TAL & Pin site infection & 34 & M & L \\
\hline 24. Lower extremity burn & None & - & 67 & M & L \\
\hline 25. Parkinson's & None & - & 73 & $\mathrm{~F}$ & L \\
\hline 26. Idiopathic & None & - & 50 & $\mathrm{~F}$ & $\mathrm{R}$ \\
\hline
\end{tabular}

Exfix, external fixator; TAL, tendo-Achilles lengthening; $T B I$, traumatic brain injury

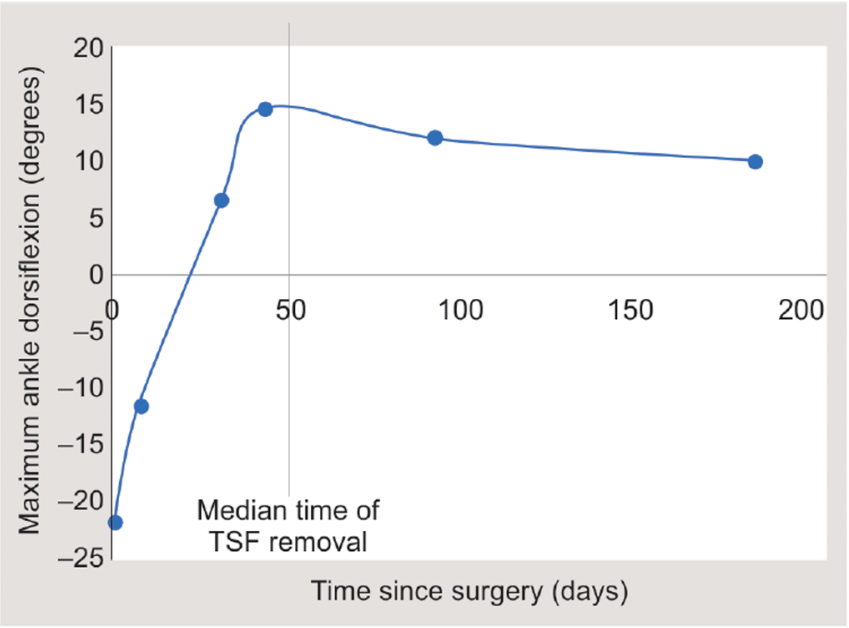

Fig. 4: Maximum degree of dorsiflexion during clinical course

There were minimal soft tissue-related complications with the most common being pin site infections. All infections resolved with debridement and oral antibiotics with no longterm consequences. There were no neurovascular injuries. One patient had a hardware failure that required frame revision for a broken pin.

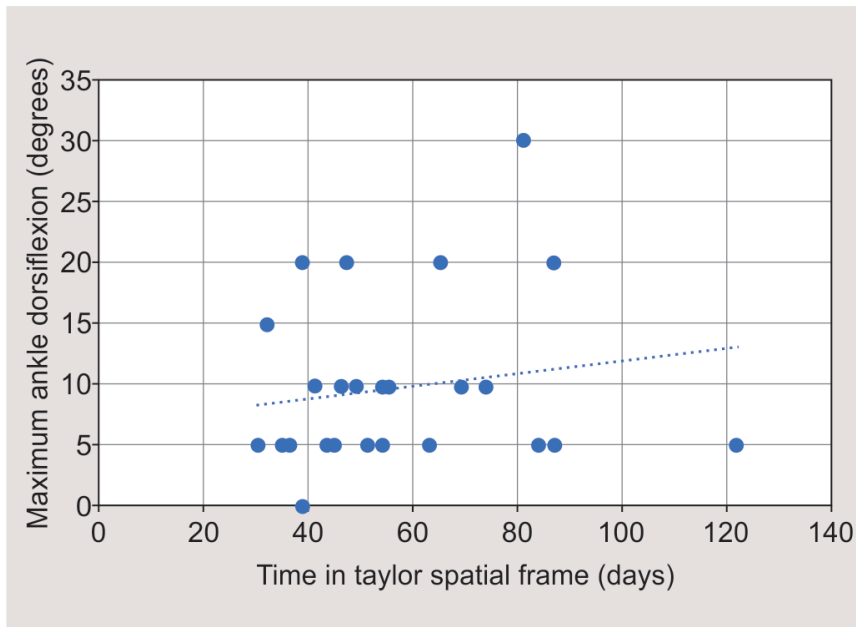

Fig. 5: Maximum degree of dorsiflexion at TSF removal (2 years)

Three patients suffered recurrence of equinus by 1 year after intervention. All three patients had suffered TBI with two of them among the most severe preoperative deformities.

This study is limited by the lack of a formal scoring system included in patient files, so we were unable to standardise subjective or objective functional outcomes after the procedure. 
Table 2: Preoperative and last follow-up angle measurements

\begin{tabular}{|c|c|c|c|}
\hline Aetiology & Time in frame (days) & Preoperative dorsiflexion & Dorsiflexion at last follow-up \\
\hline 1. Post-traumatic & 43 & -25 & 10 \\
\hline 2. Post-traumatic & 55 & -35 & 5 \\
\hline 3. Post-traumatic & 30 & -35 & 15 \\
\hline 4. Post-traumatic & 45 & -20 & 5 \\
\hline 5. Post-traumatic & 39 & -35 & 5 \\
\hline 6. Post-traumatic & 49 & -5 & 5 \\
\hline 7. Post-traumatic & 39 & -25 & 5 \\
\hline 8. Post-traumatic & 122 & -10 & 10 \\
\hline 9. Post-traumatic & 87 & -5 & 5 \\
\hline 10. Post-traumatic & 36 & -5 & 5 \\
\hline 11. Post-traumatic & 69 & -5 & 10 \\
\hline 12. TBI & 63 & -40 & 20 \\
\hline 13. TBI & 81 & -40 & 10 \\
\hline 14. TBI & 84 & -15 & 30 \\
\hline 15. TBI & 54 & -10 & 5 \\
\hline 16. TBI & 54 & -10 & 5 \\
\hline 17. TBI & 41 & -20 & 5 \\
\hline 18. Surgical complication & 32 & -5 & 20 \\
\hline 19. Surgical complication & 36 & -20 & 5 \\
\hline 20. Charcot-Marie-Tooth & 35 & -20 & 10 \\
\hline 21. Prolonged bed rest/ICU stay & 74 & -35 & 0 \\
\hline 22. Spinal cord pathology & 87 & -20 & 10 \\
\hline 23. Stroke & 46 & -30 & 5 \\
\hline 24. Lower extremity burn & 51 & -25 & 10 \\
\hline 25. Parkinson's & 47 & -25 & 20 \\
\hline 26. Idiopathic & 65 & -10 & 20 \\
\hline
\end{tabular}
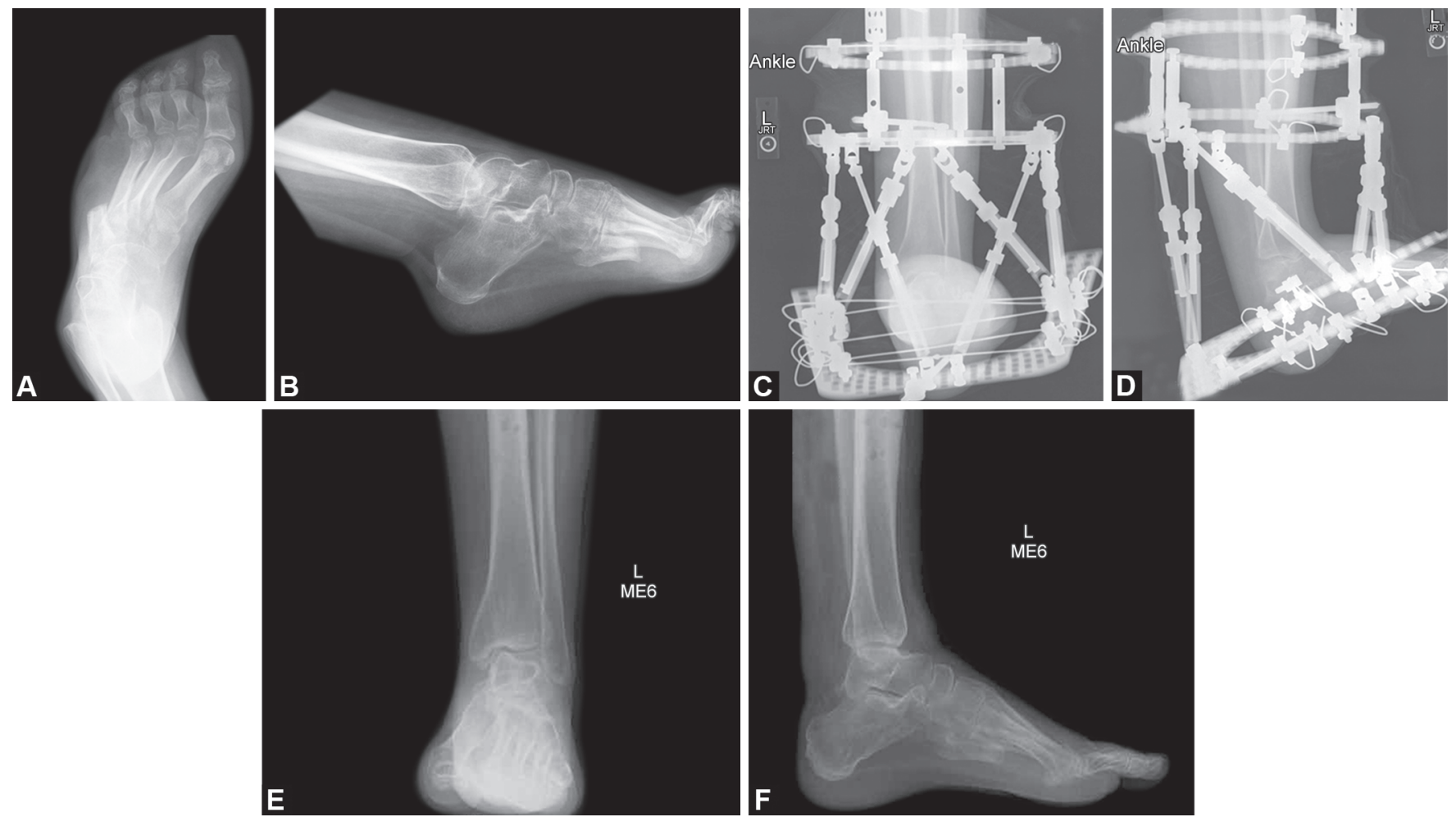

Figs 6A to F: (A and B) Forty-two-year-old man with post-traumatic ankle equinus deformity; (C and D) TSF used to correct his deformity; (E and F) Radiographs after removal of the frame 


\section{Conclusion}

This study demonstrates that the use of the TSF is able to correct equinus deformity without the need for extensive soft tissue dissection and its attendant potential complications. Adding a TAL to facilitate overcorrecting the ankle in cases of severe equinus deformity more than $25^{\circ}$ of deformity may be necessary. Overcorrection is mandatory to prevent recurrence of the deformity after frame removal but we found no added benefit from having the frame kept in situ for an extended period after correction and reaching the desired angle.

\section{References}

1. Wren TA, Do KP, Kay RM. Gastrocnemius and soleus lengths in cerebral palsy equinus gait-differences between children with and without static contracture and effects of gastrocnemius recession. J Biomech 2004;37(9):1321-1327. DOI: 10.1016/j.jbiomech.2003.12.035.

2. Orendurff MS, Aiona MD, Dorociak RD, et al. Length and force of the gastrocnemius and soleus during gait following tendo Achilles lengthenings in children with equinus. Gait Posture 2002;15(2):130135. DOI: 10.1016/S0966-6362(01)00154-0.

3. Hahn SB, Park HJ, Park HW, et al. Treatment of severe equinus deformity associated with extensive scarring of the leg. Clin Orthop Relat Res 2001(393):250-257. DOI: 10.1097/00003086-20011200000028.

4. Hsu KY, Kuo KN, Hsu RW. Correction of foot deformity by the llizarov method in a patient with Segawa disease. Clin Orthop Relat Res 1995(314):199-202. DOI: 10.1097/00003086-199505000-00026.

5. Katoulis EC, Boulton AJ, Raptis SA. The role of diabetic neuropathy and high plantar pressures in the pathogenesis of foot ulceration. Horm Metab Res 1996;28(4):159-164. DOI: 10.1055/s-2007979152.

6. Fernando DJ, Masson EA, Veves A, et al. Relationship of limited joint mobility to abnormal foot pressures and diabetic foot ulceration. Diabetes Care 1991;14(1):8-11. DOI: 10.2337/diacare.14.1.8.

7. Carmichael KD, Maxwell SC, Calhoun JH. Recurrence rates of burn contracture ankle equinus and other foot deformities in children treated with ilizarov fixation. J Pediatr Orthop 2005;25(4):523-528. DOI: 10.1097/01.bpo.0000161093.31092.c4.

8. Steinwender G, Saraph V, Zwick EB, et al. Complex foot deformities associated with soft-tissue scarring in children. J Foot Ankle Surg 2001;40(1):42-49. DOI: 10.1016/S1067-2516(01)80040-5.

9. McCarthy RE, Mulliken JB. A method for treating severe burn contractures of the tendoachilles in children. J Pediatr Orthop 1982;2(2):177-181. DOI: 10.1097/01241398-19820202000010.
10. Serletti JM, Schingo Jr VA, Deuber MA, et al. Free tissue transfer in pediatric patients. Ann Plast Surg 1996;36(6):561-568. DOI: 10.1097/00000637-199606000-00001.

11. Segev $E$, Wientroub $S$, Kollender $Y$, et al. A combined use of a free vascularised flap and an external fixator for reconstruction of lower extremity defects in children. J Orthop Surg (Hong Kong) 2007;15(2):207-210. DOI: 10.1177/230949900701500217.

12. Lin SS, Lee TH, Wapner KL. Plantar forefoot ulceration with equinus deformity of the ankle in diabetic patients: the effect of tendo-achilles lengthening and total contact casting. Orthopedics 1996;19(5): 465-475.

13. Kocaoglu M, Eralp L, Atalar AC, et al. Correction of complex foot deformities using the ilizarov external fixator. J Foot Ankle Surg 2002;41(1):30-39. DOI: 10.1016/S1067-2516(02)80007-2.

14. Jeong BO, Kim TY, Song WJ. Use of llizarov external fixation without soft tissue release to correct severe, rigid equinus deformity. J Foot Ankle Surg 2015;54(5):821-825. DOI: 10.1053/j.jfas.2014.12.039.

15. Emara K, El Moatasem el H, El Shazly O. Correction of complex equino cavo varus foot deformity in skeletally mature patients by llizarov external fixation vs staged external-internal fixation. Foot Ankle Surg 2011;17(4):287-293. DOI: 10.1016/j.fas.2010.12.001.

16. Huang SC. Soft tissue contractures of the knee or ankle treated by the Ilizarov technique. high recurrence rate in 26 patients followed for 3-6 years. Acta Orthop Scand 1996;67(5):443-449. DOI: 10.3109/17453679608996665.

17. Emara $\mathrm{KM}$, Allam MF, Elsayed MN, et al. Recurrence after correction of acquired ankle equinus deformity in children using Ilizarov technique. Strategies Trauma Limb Reconstr 2008;3(3):105-108. DOI: 10.1007/s11751-008-0045-9.

18. Ullmann $Y$, Fodor $L$, Soudry $M$, et al. The Ilizarov technique in joint contractures and dislocations. Acta Orthop Belg 2007;73(1):77-82.

19. lobst C. Pediatric joint contractures. In: Pediatric Lower Limb Deformities. Springer; 2016. pp 163-179.

20. Rozbruch SR, llizarov S. Limb lengthening and reconstruction surgery. CRC Press; 2006.

21. Paley D. Principles of deformity correction. Springer; 2014.

22. Eidelman M, Katzman A. Treatment of complex foot deformities in children with the Taylor spatial frame. Orthopedics 2008;31(10).

23. Lamm BM, Standard SC, Galley IJ, et al. External fixation for the foot and ankle in children. Clin Podiatr Med Surg 2006;23(1):137-166. DOI: 10.1016/j.cpm.2005.10.007.

24. Ferreira RC, Costa MT, Lotti $C$, et al. Minimally invasive surgery using the circular external fixator to correct neglected severe stiff equinocavus foot deformities. Foot Ankle Orthop 2018;3(3). DOI: 10.1177/2473011418789370.

25. Fadel M, Hosny G. The Taylor spatial frame for deformity correction in the lower limbs. Int Orthop 2005;29(2):125-129. DOI: 10.1007/s00264004-0611-9. 